\title{
Le patrimoine de Pandore
}

\section{Francis Debyser}

\section{OpenEdition}

\section{Journals}

Édition électronique

URL : http://journals.openedition.org/ries/4245

DOI : 10.4000/ries.4245

ISSN : 2261-4265

\section{Éditeur}

Centre international d'études pédagogiques

\section{Édition imprimée}

Date de publication : 1 septembre 1994

Pagination : 119-130

ISSN : 1254-4590

\section{Référence électronique}

Francis Debyser, «Le patrimoine de Pandore », Revue internationale d'éducation de Sèvres [En ligne], 03 | 1994, mis en ligne le 17 avril 2015, consulté le 20 avril 2019. URL : http://journals.openedition.org/ ries/4245; DOI : 10.4000/ries.4245

Ce document a été généré automatiquement le 20 avril 2019

(c) Tous droits réservés 


\title{
Le patrimoine de Pandore
}

\author{
Francis Debyser
}

1 Le Conseil de l'Europe, depuis sa création en 1949, et la Commission européenne, à partir des années 1980 puis en 1989 avec le lancement du programme Lingua, tiennent en plusieurs langues le même langage et font aux États les mêmes recommandations: l'Europe sera multilingue et pluriculturelle - toutes les langues ont la même dignité et doivent de ce fait bénéficier du même statut.

2 Trois arguments reviennent dans ce que l'on peut considérer à la fois comme une politique linguistique et comme un idéal culturel.

3 Un argument pratique : la mobilité des personnes, des biens, des capitaux et des services, objectif de l'Europe communautaire du traité de Maastricht, sera encouragée et facilitée si les jeunes Européens parlent et comprennent plusieurs langues, acceptent et comprennent plusieurs cultures (la leur, plus deux autres, conseillent les éducateurs et les linguistes).

4 Un argument culturel : l'Europe qui se construit n'est pas un melting pot indifférencié. C'est la diversité des cultures qui fait la richesse du patrimoine européen ; cette diversité s'exprime entre autres par celle des langues. Pour que les communautés linguistiques adhèrent à ce projet, il faut que ce patrimoine pluriel fait de différences, et donc d'exceptions, soit préservé et garde sa richesse.

Un argument éthique enfin, le respect des langues et des cultures comme un droit : d'où le terme de charte utilisé à propos des langues et des cultures dites minoritaires.

6 En 1989, la convergence entre Bruxelles (Commission européenne de l'Europe des douze) et Strasbourg, siège du Conseil de la coopération culturelle du Conseil de l'Europe (Europe des 24 devenue cinq ans plus tard des 32), est complète : le 15 novembre 1989 en effet se conclut l'appel d'offres à Bruxelles pour le programme Lingua prévu pour cinq ans; du 7 au 11 novembre 1989 se tient à Sintra, au Portugal, et à l'initiative du Conseil de l'Europe, un symposium sur le thème "Apprentissage et didactique des langues pour une citoyenneté européenne pluriculturelle ». Ce symposium doit également définir un plan d'action pour cinq ans. 
7 C'est pendant le symposium de Sintra que les congressistes apprennent avec enthousiasme la chute du mur de Berlin qui va entraîner celle du rideau de fer. Celui-ci coupait l'Europe en deux : une Europe de l'Ouest et une Europe de l'Est, rien au milieu, sinon un mur.

8 Mais après l'euphorie, sont venues les inquiétudes et les doutes; les années suivantes nous apportent quelques enseignements dont certains sont amers. La construction européenne s'avère plus difficile que prévue du fait de la crise économique. Quelle mobilité dans l'emploi un Européen peut-il attendre dans un environnement de pays tous atteints par le chômage? Le thème, porteur d'espoir, de l'identité plurielle faite de différences qui s'enrichissent mutuellement est contredit, ici, par la résurgence de la barbarie (crise yougoslave), là, par le divorce (scission de la Tchécoslovaquie), ailleurs, par des suspicions qui perdurent (par exemple entre les communautés linguistiques belges). Enfin, l'argument économique risque un jour d'être posé à nouveau : à Strasbourg comme à Bruxelles, on a constamment rappelé que la diversité des langues, et partant, des cultures était une chance, un atout, une "plus-value » de l'Europe. Mais qu'en est-il du surcoût ? Et si la plus-value n'était que symbolique, alors que le prix à payer est un surcoût réel et chiffrable, par exemple celui des frais d'interprétation et de traduction que connaîtra l'Union européenne lorsqu'elle comptera seize États membres et douze langues officielles?

On parle déjà, tout en la récusant, d'une Europe à géométrie variable, avec un «noyau dur» opposé implicitement à ses partenaires plus faibles. Ne risque-t-on pas de voir proposer un noyau de langues de travail « fortes » ou « porteuses », par exemple l'anglais, le français, l'allemand et l'espagnol, pour ne pas éparpiller les efforts et l'argent ? Revenir à quatre ou cinq langues signifierait dire adieu aux langues « $\operatorname{modimes}^{1} »$.

10 L'Europe est de fait aujourd'hui un laboratoire de politique linguistique où l'on a, avec les meilleures intentions du monde, ouvert une boîte de Pandore dont nous n'avons pas encore mesuré les contradictions, même si certaines sont flagrantes: ainsi le catalan parlé par six millions de locuteurs et compris par trois autres millions, du fait de son statut de langue régionale (officielle certes, mais seulement en Catalogne), ne peut-il bénéficier des subventions du programme Lingua qui peuvent en revanche se porter en faveur du luxembourgeois, parlé par moins de 350000 locuteurs.

11 En revanche, le Conseil de l'Europe a concouru activement à la résurgence du catalan et du basque, dans la logique de la Charte des langues régionales et minoritaires, souvent évoquée dans ce numéro.

12 En d'autres termes, le problème des langues régionales ou minoritaires, leurs enjeux éducatifs, les chances qu'elles apportent mais aussi les replis qu'elles peuvent impliquer, est bien, à de nombreux égards, une simulation en réduction des obstacles et des difficultés qu'aura à résoudre, pour la gestion des langues nationales, une Europe unie soucieuse d'aménager au mieux, comme l'annonce le nouveau programme Socrate, « L'espace européen de l'éducation ».

13 Au fond de la boîte de Pandore, nous dit le mythe, reste l'espérance. 


\section{NOTES}

1. Langues MO(ins) Dl(ffusées) et M(oins) E(nseignées).

\section{RÉSUMÉS}

Les contradictions et les difficultés éprouvées pour gérer les langues régionales ou minoritaires dans le cadre national reproduisent à l'échelle de l'Europe celles que connaissent les langues nationales, car l'objectif, affiché par les institutions communautaires, d'un plurilinguisme libérateur s'y trouve aussi menacé par la crise économique, les choix budgétaires et la résurgence des nationalismes.

\section{INDEX}

Mots-clés : politique linguistique, langue régionale, langue de minorité Index géographique : Europe

\section{AUTEUR}

\section{FRANCIS DEBYSER}

Centre international d'études pédagogiques (CIEP). 